\title{
Fatigue damage and environment interaction of polyester aluminized glass fiber composites
}

\author{
J.M. Ferreira ${ }^{\text {a,* }}$, J.T.B. Pires ${ }^{\text {b }}$, J.D. Costa ${ }^{\text {a }}$, O.A. Errajhi ${ }^{\text {c }}$, M. Richardson ${ }^{\text {c }}$ \\ ${ }^{a}$ ICEMS, Department of Mechanical Engineering, University of Coimbra, 3030 Coimbra, Portugal \\ ${ }^{\mathrm{b}}$ Department of Industrial Engineering, ESTCB, IPCB, 6000-767 Castelo Branco, Portugal \\ ${ }^{\mathrm{c}}$ Mechanical and Design Engineering Department, Portsmouth University, Portsmouth, Hanta PO12 2UP, UK
}

Available online 15 November 2005

\begin{abstract}
Aluminized glass fiber composites in a polyester matrix were used in this work in an attempt to study their fatigue resistance under both dry and water saturated ambient conditions (compared to conventional glass fiber composites). These composites, containing specially modified fibers, exhibit increased thermal and electrical conduction properties whilst still being potentially adequate for many structural applications. The fatigue tests were performed in tension at ambient temperature and a frequency of $10 \mathrm{~Hz}$. The fatigue damage of aluminized composites are described and evaluated in under environmental conditions and compared to the performance of uncoated fiber composites.
\end{abstract}

(C) 2005 Elsevier Ltd. All rights reserved.

Keywords: Aluminized glass fibers; Fatigue damage; Environmental effects

\section{Introduction}

Surface aluminized glass fiber can be used to produce composite materials with interesting advantages, namely the improved thermal and electrical conduction, as well as modified impact and fatigue properties. Until now this innovative material has only been used in military applications.

Glass fibers currently used to general purpose composites production have relatively high-strength and high modulus. Some types of glass fibers have high heat resistance or particular dielectric characteristics. For some applications these specially coated fiber modified composites could offer some innovative advantages, such as increased thermal and electrical conduction, providing their basic mechanical properties are retained at a reasonable level. Also it should be noted that, because electrical fiber conductivity and/or

\footnotetext{
${ }^{*}$ Corresponding author. Tel.: +351239790700; fax: +351239790701. E-mail address: martins.ferreira@dem.uc.pt (J.M. Ferreira).
}

optical fibers are widely used to "self monitor" fatigue damage [1-6] of composite laminates, this could be a useful side benefit.

All polymers and composites absorb moisture to some extent in humid atmospheres or when submersed in water. The absorbed moisture promotes a gradual degradation of fiber interfaces and a reduction of mechanical properties $[7,8]$ such as tensile strength [9]. Some studies of moisture absorption in composite assume the process is governed by one-dimensional diffusion based on Fick's law. Other researchers consider that the process to be non-Fickian, because of factors such as the viscoelastic nature of polymers and resulting cracks. There is abundant literature on Fickian or non-Fickian diffusion effects [10-14]. The moisture diffusion process depends on factors such as: volume fraction of contents; void volume; humidity; temperature and additives.

This paper reports an experimental study of the fatigue damage and fatigue properties of these novel materials and their interaction with humid environments, particularly the water absorption and its effect on fiber interface 
degradation. Failure mechanisms and properties are compared with uncoated glass fiber composites in order to understand how possible thermal and electrical advantages may be off-set by expected loss of strength.

\section{Materials and experimental procedures}

This study involved unidirectional hand lay-up composites using an unsaturated polyester "Norpol 444-M 888" mixed with catalyst "Methyl Ethyl Ketone Peroxide 50\% solution in phthalate UN 2563" supplied by Reichhold UK Ltd. The release mould agent "Silside" supplied by Arrow Chemicals UK Ltd. was used throughout. The aluminized unidirectional E-glass fibers employed in this investigation were supplied by Chemring Group plc in one-meter length hanks, each hank having 100,000 fibers. The fibers were cut to the desired length. Laminates were fabricated in a mould of dimension $200 \times 150 \times 3 \mathrm{~mm}$. Fibers were placed carefully in the mould and initially consolidated after each layer using a roller. Three layers were used to produce a laminate approximately $3 \mathrm{~mm}$ thick. The complete assembly was placed in a hydraulic press machine with a pressure of 30 bar applied for $2 \mathrm{~h}$. After this, the samples were left to cure for $24 \mathrm{~h}$ at room temperature. The samples were removed and the panels were cut into test specimens using a circular diamond blade saw. Two series of aluminized composite were produced with volume fraction $\left(V_{\mathrm{f}}\right)$ of 0.38 and 0.41 . Another series of composites were manufactured using uncoated glass fibers with $V_{\mathrm{f}}=0.42$.

The tensile properties were determined using an electromechanical Instron Universal Testing machine. The fatigue tests were carried out on a servo-hydraulic Instron machine in constant amplitude loading.

All fatigue tests were performed in tension with a stress ratio of 0.05 and a frequency of $10 \mathrm{~Hz}$, at room temperature. The specimen geometry used in tensile and fatigue tests is shown in Fig. 1.

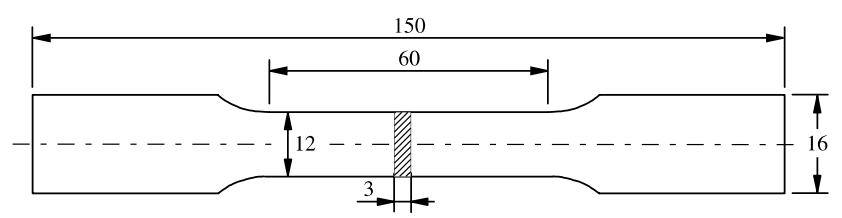

Fig. 1. Specimen dimensions for fatigue and tensile tests.

\section{Results and discussion}

Table 1 presents the tensile test results in terms of the average value and the standard deviation of the ultimate strength for the four tests performed for each fiber type and specimen storage condition. The values of the longitudinal tensile strength depend of the volumetric fraction [15] of fibers and the defects developed during fabrication. However, in this case the volume fractions for each series are very close. It seems that the great differences in strength observed are mainly linked to the fiber coating and the interfacial degradation which occurs as a consequence of water diffusion effects. An abrupt decrease in tensile strength in the coated specimens (about $77 \%$ ) is observed when compared to the uncoated fiber composites. The immersion of specimens in water for 30 and 60 days also causes a decrease in ultimate strength of about $20 \%$ and $25 \%$, respectively compared to the coated specimens stored in dry air.

The fatigue tests were performed in order to compare the fatigue strength of aluminized fiber composites with uncoated fiber composites and to study water degradation effects on damage and fatigue strength and on the failure mechanisms.

Fig. 2(a) presents the fatigue results in terms of stress range $\Delta \sigma$ versus fatigue life. The results present a similar trend for all the specimens although in some cases there is significant scatter. Coated fiber composites show much lower fatigue strength than similar composites manufactured with uncoated fibers. This significant decrease in fatigue strength of the coated composite may be caused by a weaker aluminum/polyester interface. Also an important decrease in fatigue strength is observed with specimens stored in water when compared to specimens stored in air. In order to analyze the fatigue tolerance, these results were plotted (in Fig. 2(b)) in terms of the non-dimensional, $\Delta \sigma / \sigma_{\text {UTS }}$ parameter versus the number of cycles to failure, where $\Delta \sigma$ is the actual stress range and $\sigma_{\text {UTS }}$ is the ultimate tensile strength. In spite of the relative low fatigue strength of aluminized glass fiber composites observed (in Fig. 2(a)), these composites present a very good fatigue tolerance, even higher than uncoated fibers as a consequence of their low tensile strength. The specimens tested after 30 and 60 days immersed in water present a very low fatigue tolerance showing (in Fig. 2(b)) values very closed to uncoated fibers. This very low fatigue tolerance must originate from interfacial degradation caused by water diffusion along the same interface.

Table 1

Specimens conditions and ultimate strength

\begin{tabular}{lccc}
\hline Series & $\sigma_{\mathrm{UTS}}(\mathrm{MPa})$ & $V_{\mathrm{f}}(\%)$ & Specimens storage \\
\hline Uncoated E-glass fiber (Unc./air) & $444 \pm 6$ & 42 & Stored in dry air \\
Aluminized E-glass fiber (Alum./air) & $100 \pm 11$ & 41 & Stored in dry air \\
Aluminized E-glass fiber (Alum./30 water) & $80 \pm 3$ & 38 & 30 days immersed in water \\
Aluminized E-glass fiber (Alum./60 water) & $75 \pm 2$ & 38 & 60 days immersed in water \\
\hline
\end{tabular}



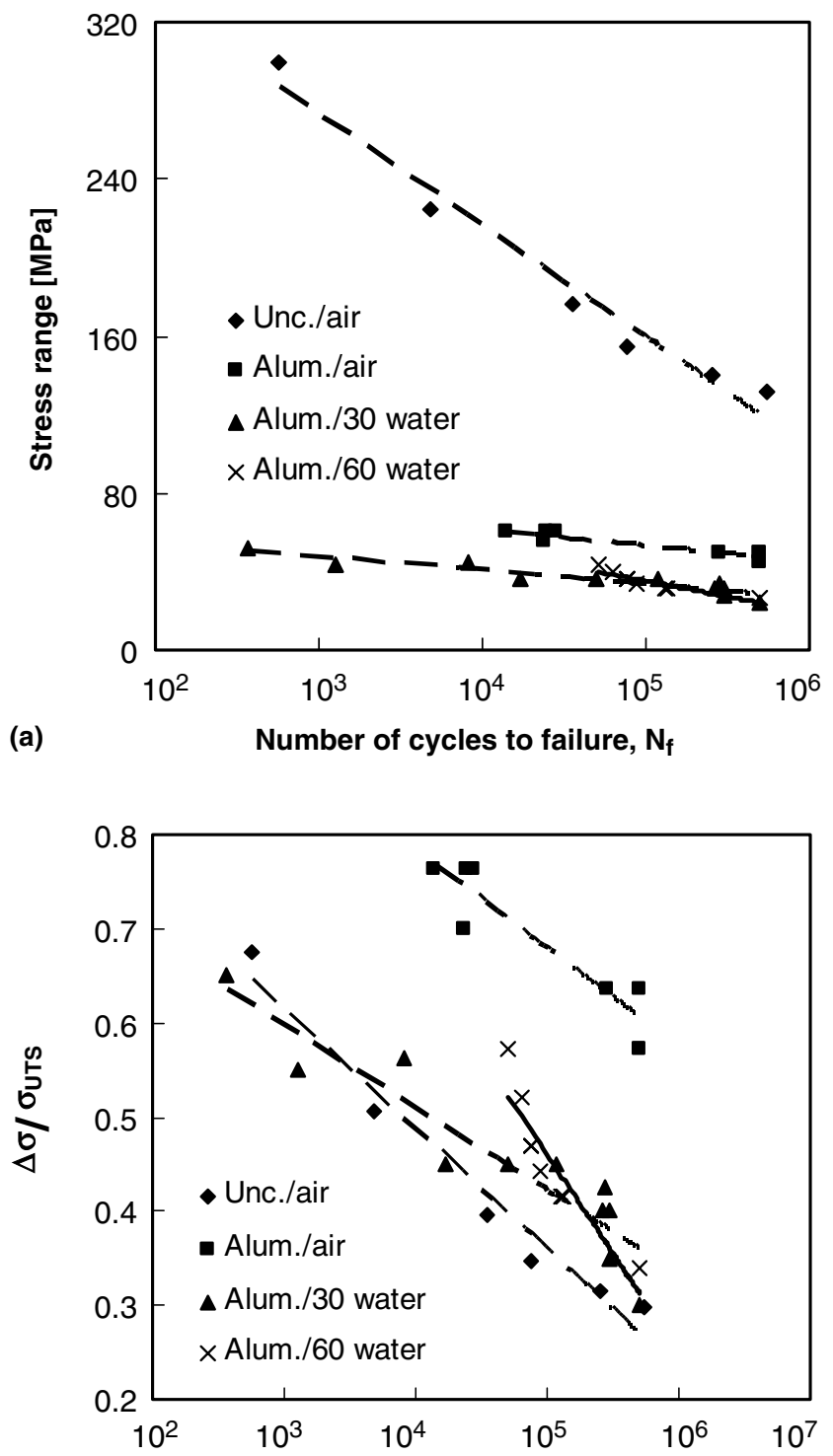

(b)

Number of cycles to failure, $\mathrm{N}_{\mathbf{f}}$

Fig. 2. Fatigue results: (a) stress range versus $N_{\mathrm{f}}$; (b) $\frac{\Delta \sigma}{\sigma_{\text {UTS }}}$ versus $N_{\mathrm{f}}$.

The water absorption of aluminized fiber composites were quantified in terms of the weight increment percentage. The water temperature was kept constant at $18^{\circ} \mathrm{C}$. The absorption results are plotted in Fig. 3, in terms of weight increment (\%) against the time (hours). The weight increment $(\%)$ was calculated by the equation $\left(W-W_{0}\right) /$ $W_{0} * 100$ where $W$ is the current weight and $W_{0}$ is the initial weight measured with an accuracy of $10^{-6} \mathrm{~N}$. The figure shows that the weight stabilizes after $30 \mathrm{~h}$ which means that the composite reaches water saturation point with a weight increment of $0.30-0.35 \%$. Consequently, the specimens immersed in water for 30 and 60 days remains water saturated during almost the all their immersion time.

The presence of the water at the interface weakens the interfacial strength and promotes some corrosion of the aluminium coating surface as can be observed in Fig. 4 . A detailed analysis of the failure surface performed by

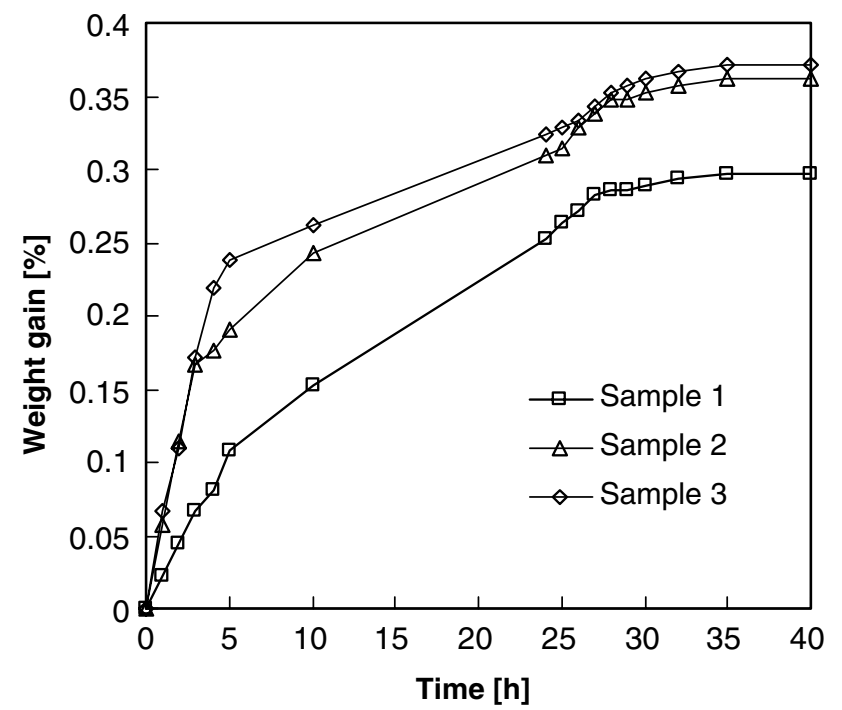

Fig. 3. Water absorption of aluminized composites at $18^{\circ} \mathrm{C}$.
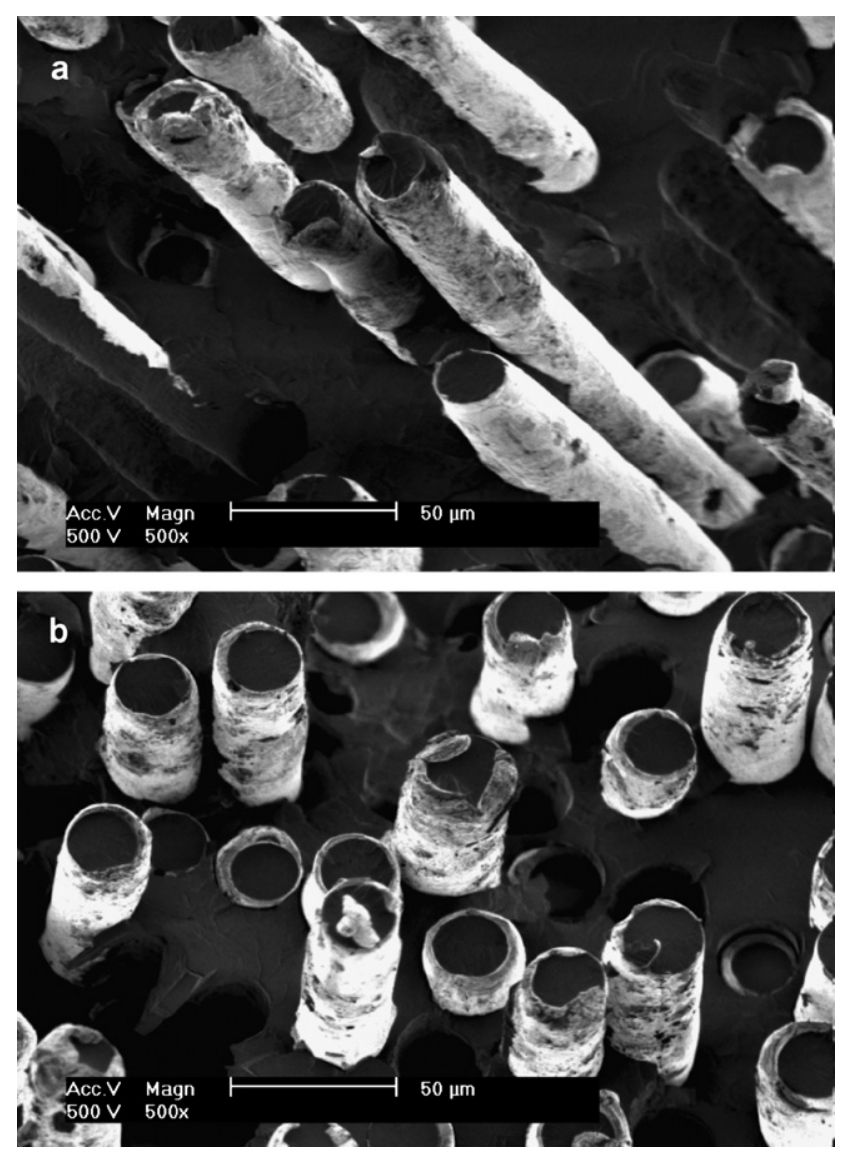

Fig. 4. Scanning electron microscope observations of the fatigue fracture surface of the specimens immersed in water: (a) 30 days; (b) 60 days.

scanning electron microscopy reveals the occurrence of corrosion points along the aluminum/polyester interface (Fig. 4(a) and (b)) which contributes towards weakening the interfacial resistance and to accelerating the fatigue failure process. This corrosion process increases with immersion 
time. In spite of the occurrence of this corrosion process it does not play a significant role because the fatigue results obtained after 30 and 60 days of water immersion are very close. The loss of the interfacial strength caused by the water effect must be the main reason why fatigue strength and fatigue tolerance decrease.

The failure surface aspect can be observed in Fig. 5 for aluminized and uncoated fiber composites, respectively. The failure aspect points to important changes in failure mechanisms and fracture planes induced by the use of aluminized fibers. The rupture of the matrix and fiber are the main failure mechanism associated with aluminized composites independent of the storage process. Fig. 4 shows pull-out fracture and fiber rupture features. Contrarily, uncoated fiber composites present predominantly interlaminar delamination failures as observed by many other authors. The decrease of fatigue strength of the water immersed specimens relative to the air stored specimens can be associated with some change in failure mechanisms: purely resin and fiber breakage for the water immersed specimens and a mixed failure process with some delamination for air stored specimens (as can be seen in Fig. 5).

Fatigue damage is quantified using the loss of stiffness during the fatigue process as a parameter of control. In fatigue tests, maximum and minimum peak stresses and strains were monitored cycle by cycle, using the stiffness modulus, $E$, defined as, the ratio between the tensile stress range and the axial strain range. The stiffness modulus variation in aluminized composites is plotted in Fig. 6 in nondimensional terms $E / E_{0}$ against $N / N_{\mathrm{f}}$, where $E_{0}$ is the initial value of $E, N$ the current number of cycles and $N_{\mathrm{f}}$ is the number of cycles to failure. Fig. $6(\mathrm{a}-\mathrm{c})$ ) are plotted for specimens stored in dry air, and immersed in water for 30 and 60 days, respectively. The results show a trend similar to the typical behavior observed for the stiffness modulus in uncoated glass fibers and in other composites such as bidirectional balanced glass fiber/PP, [16]. However, drops in stiffness modulus during early cycles

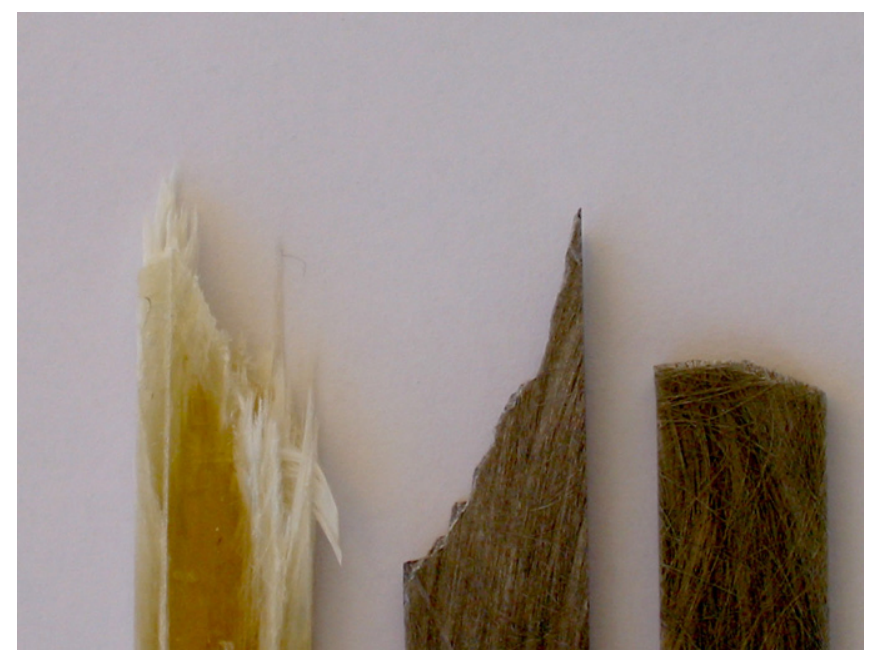

Fig. 5. Failure aspect: uncoated fibers (left); aluminised fibers stored in air (center) and immersed in water (right).
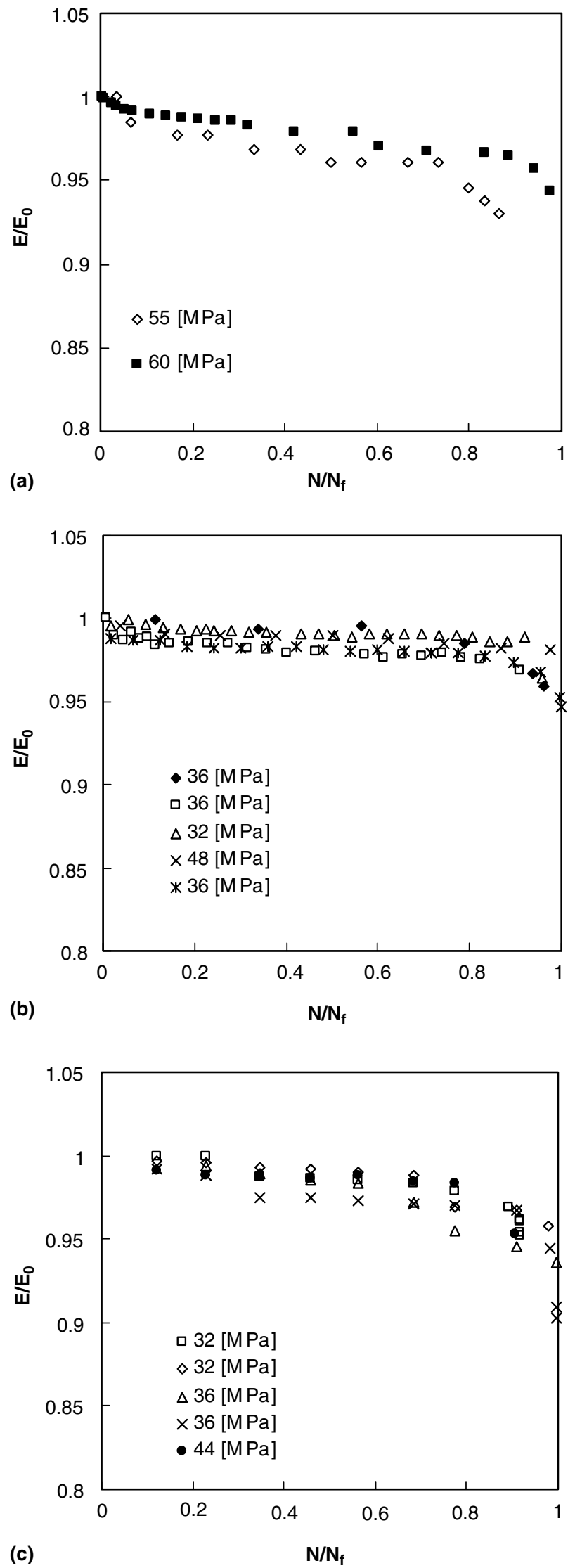

Fig. 6. $E / E_{0}$ against the normalized $N / N_{\mathrm{f}}$ number of cycles. (a) Aluminized E-glass/air; (b) Aluminized E-glass/30 water; (c) Aluminized Eglass $/ 60$ water. 
of the fatigue life caused by creep and/or resin breakage do not play a significant role. There is a very slow decrease, almost linear, particularly in water immersed specimens, of the stiffness modulus until $80 \%$ of the fatigue life followed by a pronounced decrease in the stiffness modulus until the final failure.

\section{Conclusions}

(i) Aluminized fiber composites present a significant lower in static and fatigue strength compared to the uncoated fiber composites as a consequence of the much lower aluminum/polyester interfacial strength.

(ii) Aluminized fiber composites immersed in water for 30 and 60 days decrease in static strength by $20 \%$ and $25 \%$, respectively, when compared to air stored coated specimens and there is also a significant drop in fatigue strength caused by coating corrosion and by interfacial degradation as a consequence of water absorption.

(iii) The fatigue failure of the uncoated fiber composites is mainly by interlaminar delamination while for aluminized fibers composites it is predominantly by fiber/ resin fracture.

(iv) Aluminized composites show a very slow decrease (almost linear) in stiffness modulus until $80 \%$ of the fatigue life, followed by a pronounced decrease in the stiffness modulus until final failure.

\section{References}

[1] Rapoff AJ, Dill HD, Sanger KB. Certification of damage tolerant composite structure. In: Proceedings of 8 th DOD/NASA/FAA conference on fibrous composites in structural design; 1990.
[2] Boller Chr, Dilger R. In-flight aircraft structure health monitoring based on smart structures technology. AGARD Conference Proceedings 531, Section 17, October 1992.

[3] Moriya K, Endo T. A study of flaw detection method for cfrp laminates - the measurement of crack extension in cfrp composites by electrical potential method. Trans Japan Soc Aerospace Sci 1990;32:184-96.

[4] Thiagarajan C, Irving PE. In service damage monitoring techniques for polymer composites. In: Proc of the Aerotech 94 (IMechE); 1994.

[5] Williamson NJ, Kemp RMJ, Curtis PT. In: Gibson AG, editor. Proceedings of the 6th international conference on fibre reinforced composites, Newcastle. London: Institute of Materials; 1994. p. 17.

[6] Fisher Chr, Arendts FJ. Electrical crack length measurement and the temperature dependence of mode I fracture toughness of carbon fibre reinforced plastic. Compos Sci Technol 1993;46:319-23.

[7] Benameur T, Haffane R, Granger R, Fergnaud JM. Resistance to water at $100{ }^{\circ} \mathrm{C}$ of unsaturated polyester coatings as a function of their state of cure. Modelling the process of cure and post cure and of diffusion. J Mater Sci Eng 1995;3:309-17.

[8] Cai LW, Weitsman Y. Non-Fickian moisture diffusion in polymer composites. J Compos Mater 2002;28(2):130-54.

[9] Collings TA. Moisture absorption-Fickian diffusion kinetics and moisture profiles. In: Jones FR, editor. Handbook of polymer fibre composites. UK: Longman Scientific; 1994. p. 366-71.

[10] Shen CH, Springer G. Moisture absorption and desorption of composite materials. J Compos Mater 1999;10:2-20.

[11] Roy S, Xu WX, Park SJ, Liechti KM. Anomalous moisture diffusion in viscoelastic polymer: modelling and testing. J Appl Mech 1987;67(2):391-6.

[12] Pritchard G, Speake SS. The use of water absorption kinetic data to predict laminate property changes. J Compos 1987;18(3):227-32.

[13] Carter HG, Kibler KG. Langmuir-type model for anomalous moisture diffusion in composite resins. J Compos Mater 1978;12:118-31.

[14] Camino G, Luda MP, Polishchuk AYa, Revellino M, Blancon R, Merle G, et al. Kinetic aspects of water sorption in polyester resin/ glass-fibre composites. Compos Sci Technol 1997;57(11):1469-82.

[15] Branco CM, Ferreira JAM, Richardson MOW, Fael P. Fatigue behaviour of a phenolic matrix composite. Int $\mathrm{J}$ Fatigue 1992;14:367-76.

[16] Ferreira JAM, Costa JDM, Richardson MOW. Effect of notch and test conditions on the fatigue of a glass-fibre-reinforced polypropylene Composite. Comp Sci Tech 1997;57:1243-8. 